L. HE, C.-F. NG, Z. LIU, D. KUCK*, H.-F. CHOW* (THE CHINESE UNIVERSITY OF HONG KONG, SHATIN, HONG KONG AND UNIVERSITÄT BIELEFELD, GERMANY)

Trefoil-Shaped Porous Nanographenes Bearing a Tribenzotriquinacene Core by Three-fold Scholl Macrocyclization Angew. Chem. Int. Ed. 2018, 57, 13635-13639.

\section{Five Points for Graphene Nanobowls!}
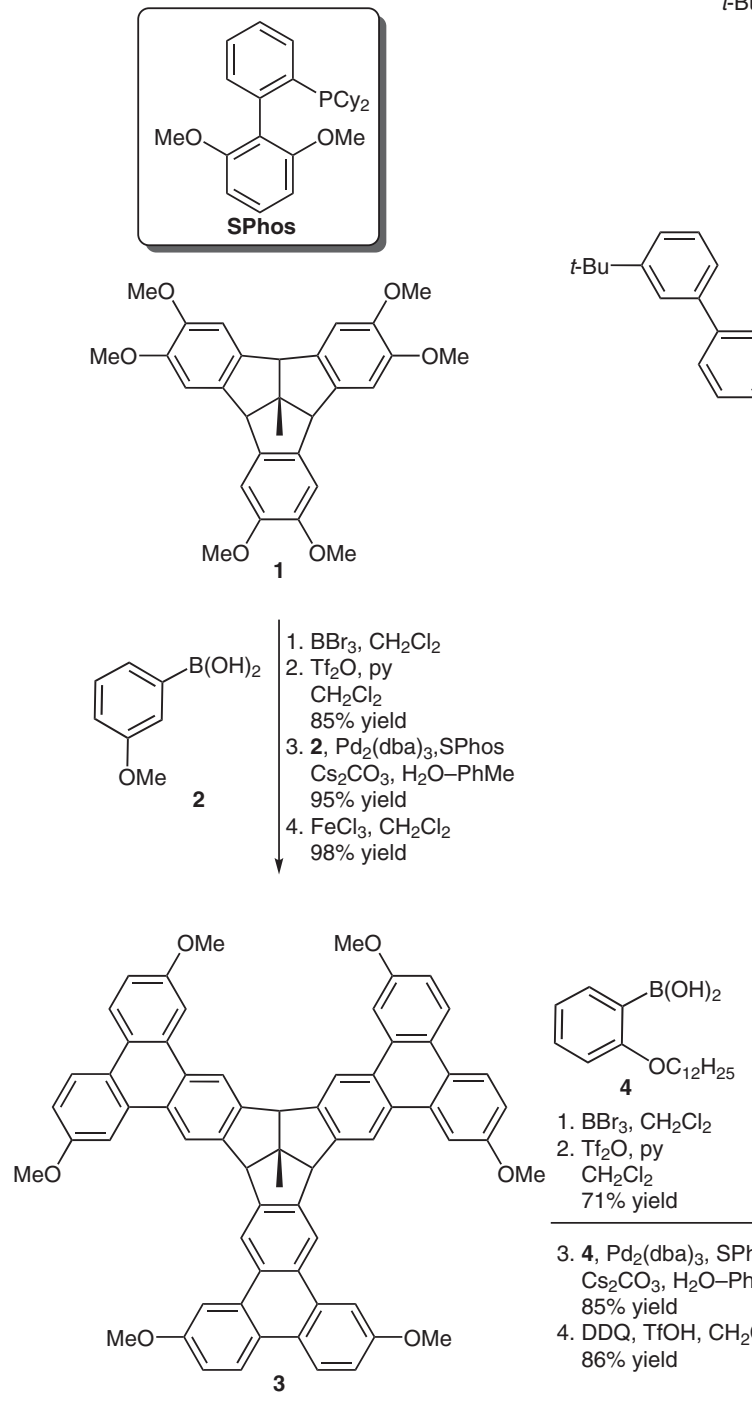

1. $\mathrm{BBr}_{3}, \mathrm{CH}_{2} \mathrm{Cl}_{2}$

2. $\mathrm{Tf}_{2} \mathrm{O}$, py

$\mathrm{CH}_{2} \mathrm{Cl}_{2}$
$71 \%$ yield

3. 4, $\mathrm{Pd}_{2}(\mathrm{dba})_{3}$, SPhos $\mathrm{Cs}_{2} \mathrm{CO}_{3}, \mathrm{H}_{2} \mathrm{O}-\mathrm{PhMe}$ $85 \%$ yield

4. DDQ, TfOH, $\mathrm{CH}_{2} \mathrm{Cl}_{2}$ $86 \%$ yield
Category

Synthesis of

Materials and

Unnatural Products

\section{Key words}

nanographenes

polycyclic aromatic hydrocarbons

Scholl cyclization

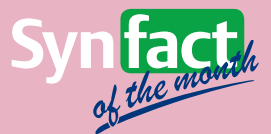

Significance: Given the difficulty of studying the chemical properties of graphene directly, many researchers have turned to the use of small molecules as model systems. In this report, the authors demonstrate the synthesis of a model system for porous nanographenes. Anion binding, electronic properties, and aggregation are probed in the final product.

SYNFACTS Contributors: Timothy M. Swager, Samuel I. Etkind Synfacts 2018, 14(11), 1137 Published online: 18.10.2018 DOI: 10.1055/s-0037-1611285; Reg-No.: S10118SF
Comment: The formation of large polycyclic aromatic hydrocarbons can be low yielding. The iterative process developed by the authors, involving the deprotection of an alkoxyphenol with $\mathrm{Br}_{3} \mathrm{~B}$, followed by triflation and subsequent SuzukiMiyaura coupling, however, allowed for the expedient synthesis of $\mathbf{5}$ in good yield. Elaboration to form $\mathbf{7}$ enabled analysis by X-ray crystallography, revealing a 'wizard-hat shaped' molecule. 